\title{
Modelling and Forecasting Volatility of Crude Oil Returns in Nigeria based on Six Error Innovations
}

Ojirobe, Yunusa Adavi ${ }^{*}$, Abdulsalam, Hussein Ahmad² \& David, Ikwuoche John ${ }^{3}$

${ }^{1,2}$ Department of Statistics, Ahmadu Bello University, Zaria, Nigeria

${ }^{3}$ Department of Mathematics and Statistics, Federal University Wukari, Taraba State, Nigeria

*Corresponding author: ojirobeyunus@gmail.com

https://doi.org/10.22452/josma.vol3no1.6

Modeling price volatility of crude oil (PVCO) is pertinent because of the overbearing impact on any oil-producing economy. This study aimed at evaluating the performance of some volatility models in modeling and forecasting crude oil returns. Utilizing daily returns data from October 23, 2009, to March 23,2020 , this study attempted to capture the dynamics of crude oil price volatility in Nigeria using a symmetric and asymmetric GARCH models. In our research, we considered the generalized autoregressive conditional heteroscedastic model (GARCH), Exponential (E-GARCH), Glosten, Jagannathan and Runkle (GJR-GARCH) and Asymmetric Power (AP-ARCH) under six error innovations that include the skewed variant of the student- $t$, generalized error and normal distribution. From the results obtained, it was discovered that the $\mathrm{AP}-\mathrm{ARCH}(1,1)$ model performed better in the fitting and performance evaluation phase. The skew Student's $t$-distribution (SStD) was also reported to be the best performing error innovation in most of the models. Based upon these results, we conclude that the AP-ARCH $(1,1)-\mathrm{SS} t \mathrm{D}$ model is the best model for capturing the dynamics of crude oil returns in Nigeria.

Keywords: AP-ARCH; Crude oil; GARCH; Skew Student's- $t$ error distribution; Volatility

\section{Introduction}

In financial time series analysis, a pertinent obstacle is the ability to design and implement efficient statistical techniques for modelling and forecasting volatility. Volatility is exhibited by some time series data such as: stock prices, exchange rate, inflation rate, commodity prices and so on. According to (Deebom et al., 2017), these variables often possess volatility clustering, which is a period wherein prices show wide swings within an extended time and later show relative calmness. It is a key indicator for decision making by investors, consumers and government alike. The idea of crude oil volatility has been gaining a lot of traction over the years, owing to the significant role it plays in the world's 
economy, particularly crude oil-dependent economies like Nigeria. It plays a dominant role in Nigeria even though there has been a recent argument about whether it still holds sway due to the current drive by the current administration to diversify the economy. According to the trade data made available by the National Bureau of Statistics for quarter four $\left(\mathrm{Q}_{4}\right), 2019$, crude oil still accounts for a whopping $76 \%$ of her foreign exchange earnings. Getting a good understanding of the dynamics of crude oil volatility is important for not only Nigeria, but the world at large because of the unquantifiable role it plays in the economy.

A plethora of literature has studied volatility in some time series variable such as crude oil price (Suleiman et al., 2015 Alhassan \& Kilishi, 2016; Muhammed \& Faruk, 2018; Zhang et al., 2019; Nguyen \& Walther, 2020;; Boitumelo et al., 2020), exchange rate (Kuhe \& Agaigbe, 2018; Abdullah et al., 2017; Okoro \& Osisiogu, 2017; Dritsaki, 2019), stock prices (Al Rahahleh \& Kao, 2018; Iwada et al., 2018; Lin, 2018; Aliyev et al., 2020), inflation (Fwaga et al., 2017; Nyoni, 2018; Iddrisu et al., 2019) amongst others. Modeling PVCO by some authors has reported varying outcomes over the years. Take for instance, (Narayan \& Narayan, 2007) studied oil price volatility and reported that there is inconsistent evidence of asymmetry and persistence in oil price returns when he considered several subsamples. No justification was however made for the various subsamples utilized. A relevant paper by (Muhammed \& Faruk, 2018) sought to investigate whether there exists a GARCH-type model that could forecast Nigerian crude oil prices. The authors utilized monthly bonny light crude oil prices data from April 1986 to December 2015 to examines several GARCH models that include the symmetric GARCH, Exponential GARCH (E-GARCH), Threshold ARCH (TARCH), and Power ARCH (PARCH). The studies outcome shows that the symmetric GARCH $(1,1)$ was found to be more parsimonious through defined criteria with a better forecast performance against other competing GARCH-type models. One limitation we identified was that it considered only the Student- $t$ and Generalized error Distribution.

Also, (Suleiman et al., 2015) empirically examined the best ARIMA and GARCH models for forecasting crude oil price in Nigeria by employing monthly data comprising of 109 observations spanning the period of January 1998 to September 2013. The authors compared several ARIMA models and based on some criteria such as AIC, BIC and HQC selected ARIMA $(3,1,1)$ as the best in fitting and forecasting. For reasons not known to us for its selection, $\operatorname{GARCH}(2,1)$ was also adjudged the best model for forecasting crude oil price series. The study is limited in the sense that it utilizes spot price for GARCH modelling instead of returns that literature has shown to possess some underlying statistical properties. Also, we observed that there was no justification as to why $\operatorname{GARCH}(2,1)$ was the preferred symmetric model to capture the dynamics of PVCO in Nigeria. 
In (Zhang et al., 2019), PVCO forecast were examined within the framework of some single-regime switching GARCH models and regime switching GARCH models. Particular interest was given to the GARCH, E-GARCH, and GJR-GARCH for single-regime switching models, with MMGARCH and MRS-GARCH being regime switching models. The study utilized daily and weekly spot price data for brent crude oil spanning the period of 02, January, 1986 to 30, June, 2017. The in-sample result indicates that the MRS-GARCH model provides better estimation accuracy in weekly data. However, the out-ofsample results indicate that regime switching has limited significance. The study concluded that based on the estimation and forecasting performance, there isn't evidence to show that the incorporation of regime switching performs better than the single-regime switching models. The paper's limitation was that it only considered the error innovation of normal distribution despite getting kurtosis that is higher than 3 , which is indicating that the return distribution is peaked rather than normal.

The contribution of (Deebom et al., 2017), was targeted at modelling price volatility in Nigeria crude oil market using the asymmetric and symmetric GARCH-family model in three distributional assumptions namely, generalized error, student's- $t$ and normal distribution. Monthly crude oil data was extracted the central bank of Nigeria database covering January 1987 to June 2017. The result obtained showed that the first-order symmetric GARCH model (GARCH $(1,1))$ under student-t error distribution gave a better fit when compared to the first-order Exponential GARCH model (E-GARCH $(1,1)$ ) under the normal error innovation. The study recommended the need to use asymmetric GARCH models when modelling volatility of price returns for both micro/macro-economic variables. The paper did not consider forecasting methodologies for accurate comparison of the best competing models.

Several studies have identified that the inclusion of skew parameter to the error innovation helps to improve the performance of GARCH-type models in modelling and forecasting volatility (Agboola et al., 2018; Samson, 2020). Despite this, no attention has been given to crude oil returns (COR) volatility modelling in Nigeria. Hence this study seeks to fill this gap in the literature. The contribution of this study to the scarce literature on crude oil return volatility modelling is centred on the objective of evaluating the performance of a symmetric and asymmetric GARCH-type models in estimating and forecasting volatility in COR under six error innovations namely: Normal distribution (ND), Skew ND (SND), Student- $t$ Distribution (StD), Skew S- $t \mathrm{D}$ (SS- $t \mathrm{D})$, Generalised Error Distribution (GED) and Skew GED (SGED). We have distinguished our study from the existing works of literature by not focusing on spot prices as seen in (Suleiman et al., 2015) but rather utilized COR. The study is also different from existing literature on crude oil price returns as it includes recent dataset spanning periods up till 2020. Finally, this study differs from existing literature on PVCO because it utilizes six error distributions for comparison in other to capture and understand the dynamics of COR. The preceding part of the paper is organized as follows: The next section discusses the data and methodology to carry 
out our analysis, with section 3 presenting the results and discussion for relevant interpretation. The last section of this study gives a summary and conclusion of the research.

\section{Data and Methodology}

\subsection{Data:}

This study utilized the daily crude oil price spanning the long stretch of October 23, 2009, to March 23, 2020. The total sample was partitioned into training/in-sample and testing/out-sample period. The training set used for estimating model parameters constitutes 1905 observations spanning October 23, 2009 , to January 28, 2019. The testing set used for the forecasting framework comprises of 235 observations from January 28, 2019, to March 23, 2020. The data were obtained from the Central Bank of Nigeria website at https://www.cbn.gov.ng/rates/crudeoil.asp. This yields a total of 2348 observations of spot price, which were then converted into logarithmic return series because it possesses some statistical properties amongst others.

Let:

$$
S_{t}=\log \left(\frac{p_{t}}{p_{t-1}}\right)
$$

where $p_{t}$ and $p_{t-1}$ represent the present crude oil spot price at time $t$ and previous crude oil spot price at time $t$-1. $S_{t}$ as shown in Eq. (1) is the continuously compounded return series which would be utilized in assessing volatility over the study period.

\subsection{Testing for Stationarity}

Stationarity test would be carried out on the CRP using the augmented dickey-fuller test. The objective is to examine the null hypothesis that $\psi=1$ in

$$
y_{t}=\psi y_{t-1}+z_{t}
$$

against the one-sided alternative $\psi<1$. Thus, the hypotheses of interest are

$\mathrm{H}_{0}$ : series contains a unit root

Versus

$$
\mathrm{H}_{\mathrm{a}} \text { : series is stationary. }
$$

\subsection{Testing for ARCH effect:}

Before we begin the process of estimating our GARCH models, it is imperative that we ascertain their appropriateness by testing for $\mathrm{ARCH}$ effect present in the residuals (i.e., presence of heteroscedasticity) and this is achieved by using LaGrange multiplier (LM) test. Upon obtaining the residual $e_{t}$, we regress the squared residual on a constant and its $q$ lags. The null hypothesis stipulates that there is no ARCH effect of order $q$ defined as: 


$$
\begin{array}{ll} 
& \mathrm{H}_{0:}(\mathrm{ARCH}) \beta_{1}=\ldots=\beta q=0 \\
& \mathrm{H}_{\mathrm{a}}(\mathrm{ARCH}) \beta_{1} \neq \ldots \neq \beta q \neq 0
\end{array}
$$

\subsection{Some GARCH- type Models}

\subsubsection{GARCH (p, q) Model}

The GARCH model can be generally expressed as:

$$
\sigma_{t}^{2}=\omega+\sum_{i=1}^{p} \alpha_{i} z_{t-i}^{2}+\sum_{j=1}^{q} \beta_{j} \sigma_{t-j}^{2}
$$

with $\omega>0, \alpha_{i}>0, \beta_{j}>0$ for $\mathrm{I}=1, \ldots, \mathrm{p}$ and $\mathrm{j}=1, \ldots, \mathrm{q} . \mathrm{p}, \mathrm{q}$ is the order of the ARCH terms $z_{t}^{2}$ and GARCH terms $\sigma^{2}$ respectively. $\sigma_{t}^{2}$ represents the conditional variance with $z_{t}^{2}$ being the disturbance term. If $\mathrm{p}=\mathrm{q}=1$ in Eq. (3), we obtain a $\operatorname{GARCH}(1,1)$ model defined as:

$$
\sigma_{t}^{2}=\omega+\alpha_{1} z_{t-1}^{2}+\beta_{1} \sigma_{t-1}^{2}
$$

Here all the parameters are $\omega, \alpha_{1}$, and $\beta_{1}>0$ (i.e. non-negative) and $\alpha_{1}+\beta_{1}<1$ to achieve stationarity.

\subsubsection{Exponential GARCH (p. q) Model}

To address the asymmetric behaviour of the leverage effect and to avoid the parameter restrictions for positivity as in the E-GARCH model defined as:

$$
\log \left(\sigma_{t}^{2}\right)=\omega+\sum_{i=1}^{q}\left\{\alpha_{i}\left|\frac{\varepsilon_{t-i}}{\sigma_{t-i}}\right|+\gamma_{i}\left(\frac{\varepsilon_{t-i}}{\sigma_{t-i}}\right)\right\}+\sum_{j=1}^{p} \beta_{j} \log \left(\sigma_{t-j}^{2}\right)
$$

where $\varepsilon_{t-i}>0$ and $\varepsilon_{t-i}<0$ connotes good news and bad news with their corresponding total effects of $\left(1+\gamma_{i}\right)\left|\varepsilon_{t-i}\right|$ and $\left(\left(1+\gamma_{i}\right)\left|\varepsilon_{t-i}\right|\right.$ respectively. $\gamma_{i}$ signifies leverage effect If $\gamma_{i}<0$, we would expect bad news to have significant impact on volatility. When $p=q=1$ in Eq. (5), a reduced form of E-GARCH $(1,1)$ is obtained as:

$$
\log \left(\sigma_{t}^{2}\right)=\omega+\alpha_{1}\left|\frac{\varepsilon_{t-1}}{\sigma_{t-1}}\right|+\gamma_{1} \frac{\varepsilon_{t-1}}{\sigma_{t-1}}+\beta_{1} \log \left(\sigma_{t-1}^{2}\right)
$$

\subsubsection{Glosten, Jagannathan and Runkle GARCH Model}

The GJR-GARCH model, models both positive and negative shocks on the conditional variance with the use of the indicator function $I$. The model specification takes the form:

$$
\sigma_{t}^{2}=\omega+\sum_{i=1}^{q}\left(\alpha_{i} \varepsilon_{t-1}^{2}+\gamma_{i} I \varepsilon_{t-1}^{2}\right)+\sum_{j=1}^{p} \beta_{j} \sigma_{t-j}^{2}
$$

where $\gamma_{i}$ signify the 'leverage' term. The indicator function $I$ takes on value of 1 for $\varepsilon \leq 0$ and 0 otherwise. If $p=q=1$, then we would have a reduced form referred as GJR-GARCH $(1,1)$ 


\subsubsection{Asymmetric Power ARCH Model}

Asymmetric power ARCH model allows for leverage effect. The specification of the model is defined as:

$$
\sigma_{t}^{\delta}=\omega+\sum_{i=1}^{q}\left(\alpha_{i}\left|\varepsilon_{t-1}\right|-\gamma_{i} \varepsilon_{t-1}\right)^{\delta}+\sum_{j=1}^{p} \beta_{j} \sigma_{t-j}^{\delta}
$$

Where $\delta \in \mathbb{R}^{\oplus}, \alpha_{i} \geq 0$ and $-1<\gamma_{i}<1 \quad \gamma_{i}$ is coefficient of the leverage effect

\subsection{Error Distribution}

In this study, we considered six types of error distributions namely: Normal, Skew normal Student-t, Skew student-t, generalized error, and Skew generalized error distribution.

2.5.1 Normal Distribution (ND): The normal or Gaussian distribution is defined as:

$$
f\left(z ; \mu, \sigma^{2}\right)=\frac{1}{\sqrt{2 \pi}} \mathrm{e}^{\frac{-z^{2}}{2}}, \quad-\infty<\mathrm{z}<\infty
$$

where $\mu$ is the location parameter which constitute the mean and $\sigma$ is the standard deviation.

2.5.2 Skew Normal Distribution (SND): The skewed normal distribution is given by;

$$
f(z)=\frac{1}{\sigma \pi} \mathrm{e}^{-\frac{(x-\varepsilon)^{2}}{2 \sigma^{2}}} \int_{-\infty}^{\alpha} \frac{z-\varepsilon}{\sigma} e^{-\frac{t^{2}}{2}} d t,-\infty \prec \mathrm{z} \prec \infty
$$

where $\varepsilon$ denotes the location parameter; $\sigma$ denotes the scale and $\alpha$ denotes the shape parameter.

2.5.3 Student-t Distribution (SD): The student-t distribution is given as;

$$
f(t ; k)=\frac{\Gamma\left(\frac{k+1}{2}\right)}{\sqrt{k \pi} \Gamma\left(\frac{k}{2}\right)}\left(1+\frac{t^{2}}{k}\right)^{\frac{-k+1}{2}}
$$

where $\mathrm{k}$ is the number of degrees of freedom, $\mathrm{t}$ variable is a real number and $\Gamma$ is the Gamma function.

2.5.4 Skew Student-t Distribution (SND): The skew student-t distribution is defined as; 


$$
\begin{aligned}
f(z ; \mu, \sigma, \theta, \lambda)=b c & {\left[1+\frac{1}{\theta-2}\left(\frac{b\left(\frac{z-\mu}{\sigma}\right)+a}{1-\lambda}\right)^{2}\right]^{\frac{\theta+1}{2}} \text { if } \mathrm{z} \prec-\frac{a}{b} } \\
b c & {\left[1+\frac{1}{\theta-2}\left(\frac{b\left(\frac{z-\mu}{\sigma}\right)+a}{1+\lambda}\right)^{2}\right]^{-\frac{\theta+1}{2}} \quad \text { if } \mathrm{z} \geq-\frac{a}{b} }
\end{aligned}
$$

where $\theta$ is the shape parameter with $2<\theta<\infty$ and $\lambda$ is the skewness parameter with $-1<\lambda<1, \mu$ and $\sigma^{2}$ are the mean and variance of the skewed student-t distribution

2.5.5 Generalized Error Distribution (GED): The generalised error distribution is given as:

$$
f(z)=\frac{k \cdot \exp \left[-0.5\left|\frac{z}{\lambda}\right|^{k}\right]}{\lambda .2^{\left(1+\frac{1}{k}\right)} \Gamma\left(\frac{1}{k}\right)} \quad \text { where } \lambda=\left[2^{\frac{-2}{k}} \frac{\Gamma\left(\frac{1}{k}\right)}{\Gamma\left(\frac{3}{k}\right)}\right]^{\frac{1}{2}}
$$

For $-\infty<z<\infty$ and $\mathrm{O}<\boldsymbol{k}<\infty$ where $\Gamma($.) is the Gamma function and $k$ is the tailthickness parameter. Note that if $k=2$, then $z$ behaves like a standard normal distribution

2.5.6 Skew Generalized Error Distribution (SGED): The skew generalized error distribution is defined as:

$$
f(z / \rho, \varepsilon, \varphi, \delta)=\frac{\rho}{2 \varphi \Gamma\left(\frac{1}{\rho}\right)} \exp \left[\frac{|z-\delta|^{\rho}}{[1+\operatorname{sign}(z-\delta) \varepsilon]^{\rho} \varphi^{\rho}}\right]
$$

for $\varphi>0,-\infty<z<\infty, \rho>0,-1<\varepsilon<1$.

$$
\varphi=\Gamma\left(\frac{1}{\rho}\right)^{0.5} \Gamma\left(\frac{3}{\rho}\right)^{-0.5} S(\varepsilon)^{-1}
$$

Where:

$$
\begin{aligned}
& \delta=2 \varepsilon S(\varepsilon)^{-1} \\
& S(\varepsilon)=\sqrt{1+3 \varepsilon^{2}-4 A^{2} \varepsilon^{2}} \\
& A=\Gamma\left(\frac{2}{\rho}\right) \Gamma\left(\frac{1}{\rho}\right)^{-0.5} \Gamma\left(\frac{3}{\rho}\right)^{-0.5}
\end{aligned}
$$

where $\rho>0$ is the shape parameter controlling height and heavy-tail, while $\varepsilon$ is the skewness parameter with $1<\varepsilon<1$. 


\subsection{Volatility Forecast Evaluation}

To evaluate the forecasting performance of the competing models, we made use of two loss functions called mean square error and mean absolute error. They are defined below as;

$$
\begin{aligned}
& \text { MAE }=c^{-1} \sum_{t=1}^{c}\left|\hat{\sigma}_{t}-\sigma_{t}\right| \\
& \text { MSE }=c^{-1} \sum_{t=1}^{c}\left(\hat{\sigma}_{t}-\sigma_{t}\right)^{2}
\end{aligned}
$$

Where c, $\sigma_{t}$ and $\hat{\sigma}_{t}$ are the out-of-sample observation, actual volatility and forecast volatility at time $t$ respectively.

\section{Results and Discussion}

An initial analysis of the crude oil returns was carried out and as shown in Table 1, we presented some descriptive statistical properties of Crude Oil Price (COP) and COR. COP reported the mean, skewness, kurtosis and standard deviation of daily crude oil spot price as $82.01,-0.03,-1.44$ and 27.90 respectively. The plot for the volatility pattern of CP series is shown in Figure 1. We can observe that the series is characterized by a noticeable up and down movement.

Table 1: Descriptive statistics of Crude oil (bonny light) spot price and returns

\begin{tabular}{cc}
\hline Statistics & Crude oil price (COP) \\
\hline Mean & 82.00777 \\
Median & 79.16000 \\
Maximum & 130.4300 \\
Minimum & 25.81000 \\
Std. Dev & 27.90114 \\
Skewness & -0.034783 \\
Kurtosis & -1.440163 \\
Jarque-Bera & 183.0307 \\
Probability & 0.000000 \\
Observation & 2113 \\
\hline Statistics & Returns of Crude oil (CRP) \\
\hline Mean & -0.00013 \\
Median & 0.00000 \\
Maximum & 0.26222 \\
Minimum & -0.25088 \\
Std. Dev & 0.02228 \\
Skewness & -0.32038 \\
Kurtosis & 36.24667 \\
Jarque-Bera & 115378.4 \\
Probability & 0.000000 \\
Observation & 2113 \\
\hline
\end{tabular}




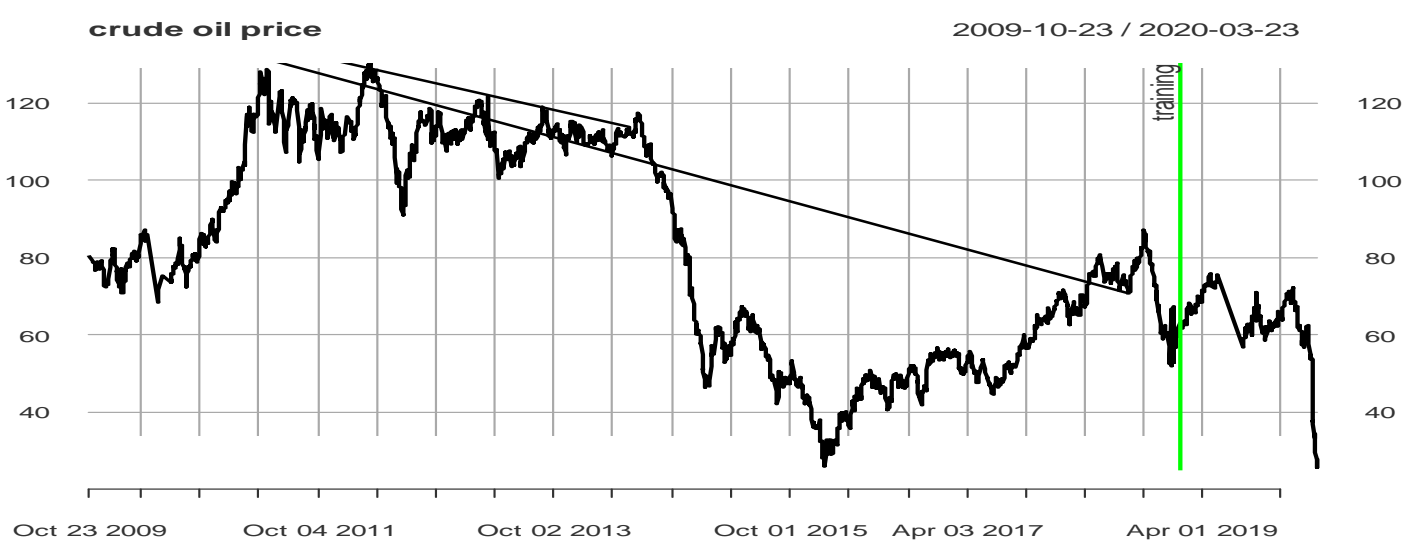

Figure 1: Daily crude oil price movement (October 23, 2009, to March, 23, 2020)

In the lower half of Table 1 , COR reports a negative mean daily return of -0.00013 with a standard deviation of 0.02228 . The maximum return was 0.26222 with a corresponding minimum of -0.25088 . COR series are negatively skewed, indicating a long-left tail and also has an excess kurtosis of 36.24667, which is greater than 3, affirming that the returns are leptokurtic (i.e. the series possesses a fat tail). The p-value associated with the Jarque-Bera test, reveals that COR deviates from the normal distribution, since the null hypothesis of normality, is rejected at $5 \%$ significant level.

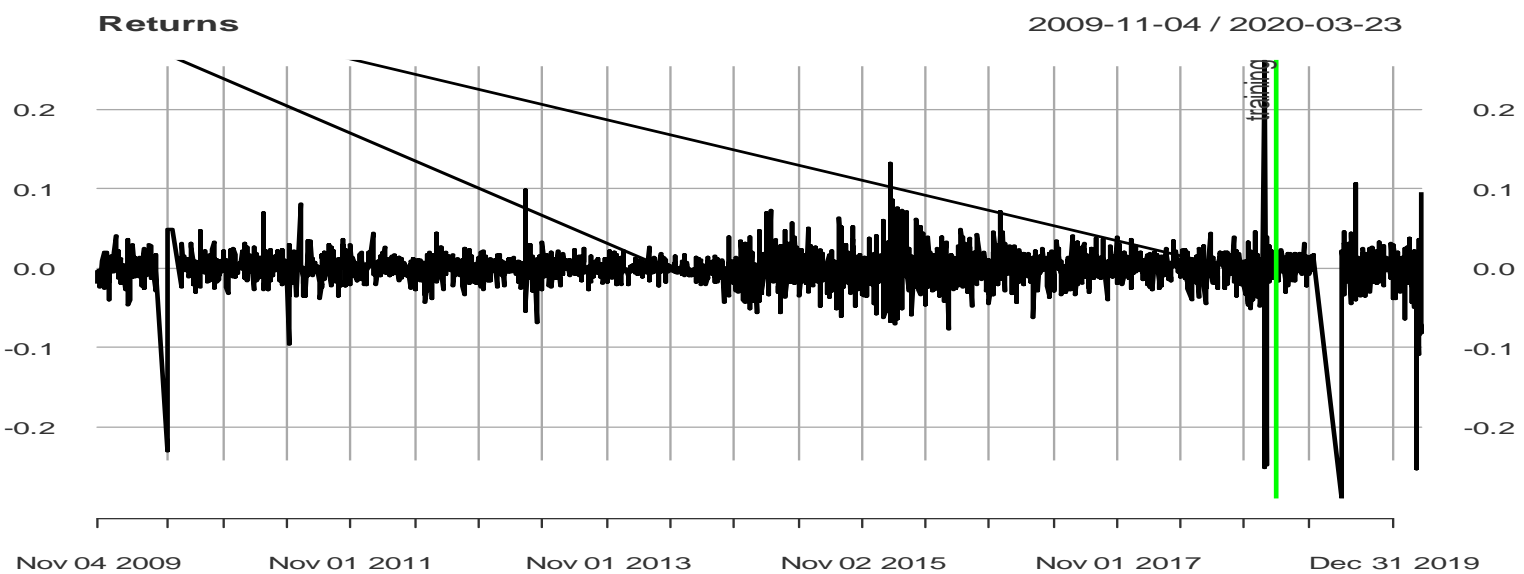

Figure 2: Daily crude oil price returns movement (October 23, 2009, to March, 23, 2020)

The COR plot in Figure 2 suggest the presence of some noticeable volatility clustering. We can observe bunches of high volatility as is the case for low volatility.

Stationarity test: The augmented dickey-fuller test was used to test for stationarity of CRP and the result is presented in Table 2 .

Table 2: Result of Unit root test using augmented dickey-fuller test (ADF) for CRP

\begin{tabular}{llll}
\hline & ADF statistics & P-value & Comment \\
\hline CRP & $-12.731^{\text {a }}$ & 0.01 & Stationary \\
\hline a signify $5 \%$ significance level &
\end{tabular}

It can be seen that the probability value of the computed tau statistics is less than 0.05 significant level. Hence, we reject the null hypothesis and accept the alternative that CRP is stationary. 
Testing for ARCH effect: Table 3 presents the outcome of the autoregressive conditional heteroscedastic $(\mathrm{ARCH})$ effect test. It is observed that the LM statistics has a very significant p-value and as such, the null hypothesis of no ARCH effect is rejected. Hence, it is evidently clear that there is the presence of ARCH effect. This is also corroborated by box test since $\mathrm{p}<0.05$ significance level.

Table 3: Result of Autoregressive conditional heteroscedastic (ARCH) effect test

\begin{tabular}{llll}
\hline CRP & F-statistic & P-value & Comment \\
\hline Box & 1289.1 & $2.2 \mathrm{e}-16^{\mathrm{a}}$ & \\
\hline LM & 888.06 & $2.2 \mathrm{e}-16^{\mathrm{a}}$ & ARCH present \\
\hline a signify $5 \%$ significance level &
\end{tabular}

Table 4a: Parameter estimation of symmetric and asymmetric GARCH models on CRP

\begin{tabular}{|c|c|c|c|c|c|c|c|c|}
\hline Model & Error & $\begin{array}{c}\omega \\
\text { (p-value) }\end{array}$ & $\begin{array}{c}\alpha_{1} \\
\text { (p-value) }\end{array}$ & $\begin{array}{c}\beta_{1} . \\
\text { (p-value) }\end{array}$ & $\begin{array}{c}\gamma_{1} . \\
\text { (p-value) }\end{array}$ & $\begin{array}{c}\delta \\
\text { (p-value) }\end{array}$ & $\begin{array}{c}\text { Skew } \\
\text { (p-value) }\end{array}$ & $\begin{array}{c}\text { Shape } \\
\text { (p-value) }\end{array}$ \\
\hline \multirow[t]{11}{*}{ E-GARCH $(1,1)$} & ND & $-0.33308^{a}$ & $-0.0627^{a}$ & $0.9554^{\mathrm{a}}$ & $0.2486^{\mathrm{a}}$ & - & - & - \\
\hline & & $(0.0000)$ & $(0.0002)$ & $(0.0000)$ & $(0.0000)$ & & & \\
\hline & SND & $-0.30336^{\mathrm{a}}$ & $-0.0669^{a}$ & $0.9593^{\mathrm{a}}$ & $0.2365^{\mathrm{a}}$ & - & $0.9422^{\mathrm{a}}$ & - \\
\hline & & $(0.0000)$ & $(0.0000)$ & $(0.0000)$ & $(0.0000)$ & & $(0.0000)$ & \\
\hline & SD & $-0.04615^{\mathrm{a}}$ & $-0.04511^{\mathrm{a}}$ & $0.9943^{\mathrm{a}}$ & $0.0804^{\mathrm{a}}$ & - & - & $5.0939^{\mathrm{a}}$ \\
\hline & & $(0.0000)$ & $(0.0000)$ & $(0.0000)$ & $(0.0003)$ & & & $(0.0000)$ \\
\hline & SSD & $-0.04586^{\mathrm{a}}$ & $-0.0449^{a}$ & $0.9943^{\mathrm{a}}$ & $0.0798^{\mathrm{a}}$ & - & $0.9742^{\mathrm{a}}$ & $5.0909^{\mathrm{a}}$ \\
\hline & & $(0.0000)$ & $(0.0000)$ & $(0.0000)$ & $(0.0164)$ & & $(0.0000)$ & $(0.0000)$ \\
\hline & GED & $\begin{array}{c}-0.09522^{\mathrm{a}} \\
(0.0000)\end{array}$ & $\begin{array}{l}0.0449^{\mathrm{a}} \\
(0.0002)\end{array}$ & $\begin{array}{l}0.9881^{\mathrm{a}} \\
(0.0000)\end{array}$ & $\begin{array}{l}0.1245^{\mathrm{a}} \\
(0.0000)\end{array}$ & - & - & $\begin{array}{c}1.1545^{\mathrm{a}} \\
(0.0000)\end{array}$ \\
\hline & SGED & $-0.09097^{\mathrm{a}}$ & $-0.0457^{\mathrm{a}}$ & $0.9886^{\mathrm{a}}$ & $0.1210^{\mathrm{a}}$ & - & $0.9769^{\mathrm{a}}$ & $1.1563^{\mathrm{a}}$ \\
\hline & & $(0.0000)$ & $(0.0001)$ & $(0.0000)$ & $(0.0000)$ & & $(0.0000)$ & $(0.0000)$ \\
\hline \multirow[t]{12}{*}{ GJRGARCH $(1,1)$} & ND & $4.1 \times 10^{-05 b}$ & $0.0719^{\mathrm{a}}$ & $0.8460^{\mathrm{a}}$ & $0.1410^{\mathrm{a}}$ & - & - & - \\
\hline & & $(0.0304)$ & $(0.0022)$ & $(0.0000)$ & $(0.0234)$ & - & - & - \\
\hline & SND & $3.1 \times 10^{-05} \mathrm{a}$ & $0.0676^{\mathrm{a}}$ & $0.8533^{a}$ & $0.1390^{\mathrm{a}}$ & - & $0.9438^{\mathrm{a}}$ & - \\
\hline & & $(0.0003)$ & $(0.0005)$ & $(0.0000)$ & $(0.0241)$ & & $(0.0000)$ & - \\
\hline & SD & $3 \times 10^{-05}$ & $0.0398^{a}$ & $0.9347^{\mathrm{a}}$ & $0.0425^{\mathrm{a}}$ & - & - & $5.2653^{\mathrm{a}}$ \\
\hline & & $(0.3253)$ & (0.0019) & $(0.0000)$ & $(0.0014)$ & & & $(0.0000)$ \\
\hline & SSD & $3 \times 10^{-05}$ & $0.0395^{\mathrm{a}}$ & $0.9354^{\mathrm{a}}$ & $0.0419^{a}$ & & $0.9799^{\mathrm{a}}$ & $5.2657^{a}$ \\
\hline & & $(0.3033)$ & (0.0009) & $(0.0000)$ & $(0.0019)$ & - & $(0.0000)$ & $(0.0000)$ \\
\hline & GED & $5 \times 10^{-05}$ & $0.0489^{\mathrm{a}}$ & $0.9165^{\mathrm{a}}$ & $0.0573^{b}$ & - & - & $1.1560^{\mathrm{a}}$ \\
\hline & & $(0.2821)$ & $(0.0041)$ & $(0.0000)$ & $(0.0219)$ & & - & $(0.0000)$ \\
\hline & SGED & $5 \times 10^{-05}$ & $0.0479^{\mathrm{a}}$ & $0.9183^{a}$ & $0.0567^{\mathrm{b}}$ & - & 0.9876 & $1.1569^{\mathrm{a}}$ \\
\hline & & $(0.3215)$ & $(0.0071)$ & $(0.0000)$ & $(0.0266)$ & - & $(0.0000)$ & $(0.0000)$ \\
\hline \multirow[t]{12}{*}{ APARCH $(1,1)$} & ND & 0.0006 & $0.1339^{\mathrm{b}}$ & $0.8704^{\mathrm{a}}$ & $0.3363^{\mathrm{a}}$ & $1.0315^{\mathrm{a}}$ & - & - \\
\hline & & $(0.5344)$ & $(0.0308)$ & $(0.0000)$ & $(0.0021)$ & $(0.0012)$ & & \\
\hline & SND & 0.0007 & $0.1250^{\mathrm{b}}$ & $0.8813^{a}$ & $0.3838^{\mathrm{a}}$ & $0.9778^{\mathrm{a}}$ & $0.9297^{\mathrm{a}}$ & \\
\hline & & $(0.4985)$ & $(0.0321)$ & $(0.0000)$ & $(0.0010)$ & $(0.0004)$ & $(0.0000)$ & \\
\hline & SD & 0.0003 & $0.0480^{\mathrm{a}}$ & $0.9604^{a}$ & $0.6429^{a}$ & $0.7536^{a}$ & - & $5.2028^{\mathrm{a}}$ \\
\hline & & $(0.0159)$ & $(0.0000)$ & $(0.0000)$ & $(0.0000)$ & $(0.0000)$ & - & $(0.0000)$ \\
\hline & SSD & $0.0003^{b}$ & $0.0478^{a}$ & $0.9608^{a}$ & $0.6440^{\mathrm{a}}$ & $0.7536^{a}$ & $0.9770^{\mathrm{a}}$ & $5.2020^{\mathrm{a}}$ \\
\hline & & $(0.0138)$ & $(0.0000)$ & $(0.0000)$ & $(0.0000)$ & $(0.0000)$ & $(0.0000)$ & $(0.0000)$ \\
\hline & GED & 0.0004 & $0.0701^{\mathrm{a}}$ & $0.9398^{a}$ & $0.4955^{a}$ & $0.8368^{a}$ & & $1.1568^{\mathrm{a}}$ \\
\hline & & $(0.2055)$ & $(0.0000)$ & $(0.0000)$ & $(0.0001)$ & $(0.0000)$ & & $(0.0000)$ \\
\hline & SGED & 0.0004 & $0.0690^{\mathrm{a}}$ & $0.9410^{\mathrm{a}}$ & $0.5064^{\mathrm{a}}$ & $0.8307^{\mathrm{a}}$ & $0.9770^{\mathrm{a}}$ & $1.1595^{\mathrm{a}}$ \\
\hline & & $(0.2677)$ & $(0.0000)$ & $(0.0000)$ & $(0.0037)$ & $(0.0000)$ & $(0.0000)$ & $(0.0000)$ \\
\hline
\end{tabular}

$P$-value are in parenthesis; $a, b$ signify significance at $1 \%$, and $5 \%$ level respectively

Haven established the presence of ARCH effect in the crude oil return series, Modelling with GARCH models became imperative and we commenced by estimating the parameter of all the 
GARCH-type models considered for this study. In Table 4a and $4 \mathrm{~b}$, the estimates of GARCH model parameters and its extensions are presented using six error distributions namely: Normal, Student-t, Generalised error distribution and their skewed variants. The results reveal that the dynamic characteristics of crude oil return volatility were captured by most of the models, due to the statistically, significant coefficients reported at $1 \%$ level of significance. ARCH and GARCH coefficient were significant for all the models, indicating that the previous day CR can influence the next day's crude oil price returns. The persistence of volatility shock is large since the sum of both ARCH and GARCH term is high. Leverage effect which measures the impact of good and bad news to returns and volatility was captured by AP-ARCH, GJR-GARCH, and E-GARCH models to be statistically significant under the six error distributions.

Table 4b: Parameter estimation of symmetric and asymmetric GARCH models on CRP

\begin{tabular}{|c|c|c|c|c|c|c|c|c|}
\hline Model & Error & $\begin{array}{c}\omega \\
\text { (p-value) }\end{array}$ & $\begin{array}{c}\alpha_{1} \\
\text { (p-value) }\end{array}$ & $\underset{\text { (p-value) }}{\alpha_{2}}$ & $\begin{array}{c}\beta_{1} \cdot \\
\text { (p-value) }\end{array}$ & $\underset{\text { (p-value) }}{\boldsymbol{\beta}_{2}}$ & $\begin{array}{c}\text { Skew } \\
\text { (p-value) }\end{array}$ & $\begin{array}{c}\text { Shape } \\
\text { (p-value) }\end{array}$ \\
\hline \multirow[t]{12}{*}{ GARCH $(1,1)$} & $\mathrm{ND}$ & $1.01 \times 10^{-05 a}$ & $0.1159^{\mathrm{a}}$ & & $0.8764^{\mathrm{a}}$ & - & - & - \\
\hline & & $(0.0000)$ & $(0.0000)$ & & $(0.0000)$ & & - & - \\
\hline & SND & $1.0 \times 10^{-05 \mathrm{a}}$ & $0.1144^{\mathrm{a}}$ & & $0.8784^{\mathrm{a}}$ & - & $0.9564^{\mathrm{a}}$ & - \\
\hline & & $(0.0000)$ & $(0.0000)$ & & $(0.0000)$ & & $(0.0000)$ & - \\
\hline & SD & $2.9 \times 10^{-06}$ a & $0.0644^{\mathrm{a}}$ & & $0.9314^{\mathrm{a}}$ & - & - & 5.1758 \\
\hline & & $(0.0088)$ & $(0.0000)$ & & $(0.0000)$ & - & - & $(0.0000)$ \\
\hline & SSD & $2.86 \times 10^{-06 a}$ & $0.0636^{\mathrm{a}}$ & & $0.9325^{\mathrm{a}}$ & - & $0.9778^{\mathrm{a}}$ & $5.1733^{\mathrm{a}}$ \\
\hline & & $(0.3387)$ & $(0.0011)$ & & $(0.0000)$ & - & $(0.0000)$ & $(0.0000)$ \\
\hline & GED & $4.89 \times 10^{-06} \mathrm{a}$ & $0.0738^{\mathrm{a}}$ & & $0.9213^{\mathrm{a}}$ & - & - & 1.1467 \\
\hline & & $(0.0000)$ & $(0.0000)$ & & $(0.0000)$ & - & - & $(0.0000)$ \\
\hline & SGED & $4 \times 10^{-06 a}$ & $0.0731^{\mathrm{a}}$ & & $0.9221^{\mathrm{a}}$ & - & $0.9904^{\mathrm{a}}$ & $1.1475^{\mathrm{a}}$ \\
\hline & & $(0.4343)$ & $(0.0110)$ & & $(0.0000)$ & & $(0.0000)$ & $(0.0000)$ \\
\hline \multirow[t]{11}{*}{$\operatorname{GARCH}(1,2)$} & ND & $\begin{array}{c}1.24 \times 10^{-05} \text { a } \\
(00000)\end{array}$ & $0.14243^{\mathrm{a}}$ & & $0.5311^{\mathrm{a}}$ & $\begin{array}{c}0.3146 \\
(0.0016)\end{array}$ & - & - \\
\hline & SND & $1.2 \times 10^{-05}$ a & $0.1420^{\mathrm{a}}$ & & $0.5215^{\mathrm{a}}$ & 0.3265 & $0.9541^{\mathrm{a}}$ & - \\
\hline & & $(0.0050)$ & $(0.0000)$ & & $(0.0082)$ & $(0.0183)$ & $(0.0000)$ & - \\
\hline & SD & $4.2 \times 10^{-06} \mathrm{a}$ & $0.09200^{\mathrm{a}}$ & & $0.4492^{\mathrm{a}}$ & 0.4531 & - & 5.2459 \\
\hline & & $(0.0327)$ & $(0.0010)$ & & $(0.0004)$ & $(0.0000)$ & - & $(0.0000)$ \\
\hline & SSD & $4.6 \times 10^{-06 a}$ & $0.0905^{\mathrm{a}}$ & & $0.4524^{\mathrm{a}}$ & 0.4513 & $0.9793^{\mathrm{a}}$ & $5.2477^{\mathrm{a}}$ \\
\hline & & $(0.3518)$ & $(0.0017)$ & & $(0.0000)$ & $(0.0000)$ & $(0.0000)$ & $(0.0000)$ \\
\hline & GED & $6 \times 10^{-06 a}$ & $0.0994^{\mathrm{a}}$ & & $0.4808^{\mathrm{a}}$ & 0.4130 & - & 1.1496 \\
\hline & & $(0.1498)$ & $(0.0000)$ & & $(0.0000)$ & $(0.0061)$ & - & $(0.0000)$ \\
\hline & SGED & $5 \times 10^{-06 a}$ & $0.0986^{\mathrm{a}}$ & & $0.4806^{\mathrm{a}}$ & $0.4148^{\mathrm{a}}$ & $0.9919^{\mathrm{a}}$ & $1.1502^{\mathrm{a}}$ \\
\hline & & $(0.0000)$ & $(0.0000)$ & & $(0.0016)$ & $(0.0047)$ & $(0.0000)$ & $(0.0000)$ \\
\hline \multirow[t]{12}{*}{$\operatorname{GARCH}(2,1)$} & ND & $1.0 \times 10^{-05} \mathrm{a}$ & $0.1160^{\mathrm{a}}$ & 0.00000 & $0.8764^{\mathrm{a}}$ & - & - & - \\
\hline & & $(0.0000)$ & $(0.0000)$ & $(0.9999)$ & $(0.0000)$ & - & - & - \\
\hline & SND & $1.0 \times 10^{-05} \mathrm{a}$ & $0.1143^{\mathrm{a}}$ & 0.00000 & $0.8785^{\mathrm{a}}$ & - & $0.9564^{\mathrm{a}}$ & - \\
\hline & & $(0.0000)$ & $(0.0000)$ & $(0.9999)$ & $(0.0000)$ & - & $(0.0000)$ & - \\
\hline & SD & $3 \times 10^{-06 a}$ & $0.0645^{\mathrm{a}}$ & 0.00000 & $0.9316^{\mathrm{a}}$ & - & - & 5.1758 \\
\hline & & $(0.0688)$ & $(0.0024)$ & $(0.9999)$ & $(0.0000)$ & - & - & $(0.0000)$ \\
\hline & SSD & $3 \times 10^{-06 a}$ & $0.0634^{\mathrm{a}}$ & 0.00000 & $0.9327^{\mathrm{a}}$ & - & $0.9777^{\mathrm{a}}$ & $5.1743^{a}$ \\
\hline & & $(0.0633)$ & $(0.0011)$ & $(0.9999)$ & $(0.0000)$ & - & $(0.0000)$ & $(0.0000)$ \\
\hline & GED & $4 . \times 10^{-06 a}$ & $0.0738^{\mathrm{a}}$ & 0.00000 & $0.9212^{\mathrm{a}}$ & - & - & 1.1466 \\
\hline & & $(0.0000)$ & $(0.0012)$ & $(0.9999)$ & $(0.0000)$ & - & - & $(0.0000)$ \\
\hline & SGED & $4 \times 10^{-06 a}$ & $0.0731^{\mathrm{a}}$ & 0.00000 & $0.9221^{\mathrm{a}}$ & - & $0.9904^{\mathrm{a}}$ & $1.1474^{\mathrm{a}}$ \\
\hline & & $(0.0000)$ & $(0.0013)$ & $(0.9999)$ & $(0.0000)$ & - & $(0.0000)$ & $(0.0000)$ \\
\hline \multirow[t]{10}{*}{ GARCH $(2,2)$} & ND & $1.2 \times 10^{-05 \mathrm{a}}$ & $0.1423^{\mathrm{a}}$ & 0.0000 & $0.5314^{\mathrm{a}}$ & 0.3162 & - & - \\
\hline & & $(0.0000)$ & $(0.0000)$ & $(0.9999)$ & $(0.0823)$ & $(0.2772)$ & - & - \\
\hline & SND & $1.2 \times 10^{-05 a}$ & $0.1421^{\mathrm{a}}$ & 0.0000 & $0.5214^{a}$ & 0.3265 & $0.9541^{\mathrm{a}}$ & - \\
\hline & & $(0.0000)$ & $(0.0000)$ & $(0.9999)$ & $(0.0000)$ & $(0.0017)$ & $(0.0000)$ & \\
\hline & SD & $4 \times 10^{-06 a}$ & $0.0920^{\mathrm{a}}$ & $1 \times 10^{-06}$ & $0.4491^{\mathrm{a}}$ & 0.4531 & - & 5.2454 \\
\hline & & $(0.0088)$ & $(0.0004)$ & $(0.9999)$ & $(0.2100)$ & $(0.8080)$ & - & $(0.0000)$ \\
\hline & SSD & $4 \times 10^{-06 a}$ & $0.0905^{\mathrm{a}}$ & $1 \times 10^{-06}$ & $0.4526^{\mathrm{a}}$ & 0.4512 & $0.9791^{\mathrm{a}}$ & $5.2448^{\mathrm{a}}$ \\
\hline & & $(0.7575)$ & $(0.0020)$ & $(0.9999)$ & $(0.0222)$ & $(0.0000)$ & $(0.0000)$ & $(0.0000)$ \\
\hline & GED & $6 \times 10^{-06 a}$ & $0.0994^{\mathrm{a}}$ & $1 \times 10^{-06}$ & $0.4808^{\mathrm{a}}$ & 0.4130 & - & 1.1496 \\
\hline & & $(0.2291)$ & $(0.0059)$ & $(0.9999)$ & $(0.1640)$ & $(0.1803)$ & - & $(0.0000)$ \\
\hline
\end{tabular}




\begin{tabular}{|c|c|c|c|c|c|c|c|}
\hline SGED & $\begin{array}{l}5 \times 10^{-06 a} \\
(0.0000)\end{array}$ & $\begin{array}{c}0.0986^{\mathrm{a}} \\
(0.0068)\end{array}$ & $\begin{array}{c}0.0000 \\
(0.9999)\end{array}$ & $\begin{array}{l}0.4814^{\mathrm{a}} \\
(0.0185)\end{array}$ & $\begin{array}{c}0.4133 \\
(0.0200)\end{array}$ & $\begin{array}{l}0.9919^{\mathrm{a}} \\
(0.0000)\end{array}$ & $\begin{array}{l}1.1501^{\mathrm{a}} \\
(0.0000)\end{array}$ \\
\hline
\end{tabular}

$P$-value are in parenthesis; $a, b$ signify significance at $1 \%$, and $5 \%$ level respectively

Table 5 presents the model selection criteria for selecting volatility model based upon their performance under the normal, student-t, generalized distribution and their skewed variant. The result gives credence to the skew student-t distribution as best error innovation when compared to the others based on its performance on GARCH $(1,1)$, GARCH $(1,2)$, GARCH $(2,1)$, GARCH $(2,2)$, E-GARCH $(1,1)$, APARCH $(1,1)$ and GJR-GARCH $(1,1)$. We can observe that the Gaussian models are mostly the least performing model since it has the least log-likelihood value and largest Akaike information criteria. This is in tandem with the results obtained by (Mattera \& Giacalone, 2018). We also observed that better results were achieved with the skewed distribution when compared to the non-skewed variant. Table 5: Model selection criteria and forecast performance evaluation of GARCH Model and some extensions 
1, 2 signifies the best \& worst performing error distribution in all the models. values in bold are the least MSE,

\begin{tabular}{|c|c|c|c|c|c|}
\hline Models & Innovation & Log-likelihood & $\overline{\mathrm{AIC}}$ & MSE & MAE \\
\hline \multirow[t]{6}{*}{$\operatorname{GARCH}(1,1)$} & ND & $5399.466^{2}$ & -5.1093 & 0.001291475 & 0.01952477 \\
\hline & SND & 5401.573 & -5.1104 & 0.001290682 & 0.01952275 \\
\hline & SD & 5597.406 & -5.2952 & 0.00128921 & 0.01952201 \\
\hline & SSD & $5597.697^{1}$ & -5.2958 & 0.001287629 & 0.01952208 \\
\hline & GED & 5568.985 & -5.2689 & 0.001288775 & 0.01952542 \\
\hline & SGED & 5569.072 & -5.2681 & 0.001288453 & 0.0195271 \\
\hline \multirow[t]{6}{*}{$\operatorname{GARCH}(1,2)$} & ND & 5401.666 & -5.1105 & 0.001291578 & 0.01952503 \\
\hline & SND & 5404.004 & -5.1117 & 0.001290682 & 0.01952275 \\
\hline & SD & $5598.630^{2}$ & -5.2954 & 0.001289333 & 0.01952212 \\
\hline & SSD & $5599.878^{1}$ & -5.2963 & 0.001288229 & 0.01952250 \\
\hline & GED & 5570.938 & -5.2698 & 0.001288878 & 0.01952236 \\
\hline & SGED & 5571.016 & -5.2698 & 0.001288345 & 0.01952266 \\
\hline \multirow[t]{6}{*}{ GARCH $(2,1)$} & ND & 5399.455 & -5.1084 & 0.001291486 & 0.0195248 \\
\hline & SND & 5401.56 & -5.1094 & 0.001290682 & 0.01952275 \\
\hline & SD & $5597.402^{2}$ & -5.2945 & 0.001289207 & 0.01952219 \\
\hline & SSD & $5597.692^{1}$ & -5.2949 & 0.001288452 & 0.0195226 \\
\hline & GED & 5568.98 & -5.2680 & 0.001288774 & 0.01952242 \\
\hline & SGED & 5569.067 & -5.2671 & 0.001288255 & 0.01952271 \\
\hline \multirow[t]{6}{*}{$\operatorname{GARCH}(2,2)$} & ND & 5401.666 & -5.1095 & 0.001291577 & 0.01952503 \\
\hline & SND & 5404.004 & -5.1108 & 0.001290734 & 0.01952289 \\
\hline & SD & $5597.630^{2}$ & -5.2953 & 0.001289333 & 0.01952212 \\
\hline & SSD & $5599.882^{1}$ & -5.2961 & 0.001288626 & 0.01952250 \\
\hline & GED & 5570.938 & -5.2689 & 0.001288873 & 0.01952273 \\
\hline & SGED & 5571.016 & -5.2688 & 0.001288348 & 0.01952266 \\
\hline \multirow[t]{6}{*}{ E-GARCH $(1,1)$} & ND & $5424.732^{2}$ & -5.1323 & 0.001287594 & 0.01952308 \\
\hline & SND & 5428.21 & -5.1347 & 0.001286461 & 0.01952666 \\
\hline & SD & 5619.66 & -5.3154 & 0.001287607 & 0.01952507 \\
\hline & SSD & $5620.035^{1}$ & -5.3160 & 0.001277981 & 0.01952334 \\
\hline & GED & 5585.279 & -5.2834 & 0.001287573 & 0.01952309 \\
\hline & SGED & 5585.709 & -5.2829 & 0.001287253 & 0.01952753 \\
\hline \multirow[t]{6}{*}{ GJR-GARCH $(1,1)$} & ND & $5414.082^{2}$ & -5.1222 & 0.001288976 & 0.01952231 \\
\hline & SND & 5417.461 & -5.1245 & 0.001287807 & 0.01952296 \\
\hline & SD & 5601.257 & -5.2978 & 0.001288549 & 0.01952354 \\
\hline & SSD & $5608.493^{1}$ & -5.2985 & 0.001279927 & 0.01952089 \\
\hline & GED & 5573.335 & -5.2721 & 0.001288413 & 0.01952262 \\
\hline & SGED & 5574.475 & -5.2713 & 0.001287524 & 0.01952312 \\
\hline \multirow[t]{6}{*}{ AP-ARCH $(1,1)$} & ND & $5425.992^{2}$ & -5.1326 & 0.001287229 & 0.01952356 \\
\hline & SND & 5431.145 & -5.1365 & 0.001285757 & 0.01952963 \\
\hline & SD & 5623.795 & -5.3183 & 0.001288417 & 0.01952318 \\
\hline & SSD & $5625.096^{1}$ & -5.3198 & 0.001275253 & 0.01951171 \\
\hline & GED & 5588.32 & -5.2853 & 0.00128825 & 0.0195335 \\
\hline & SGED & 5588.774 & -5.2848 & 0.001287087 & 0.01954822 \\
\hline
\end{tabular}

MAE and AIC.

Table 5 also presents the forecasting performance of the GARCH models and its extension using two loss functions namely: the mean square error (MSE) and mean absolute error (MAE). It has been documented that MSE is influenced by the presence of outlier and as such the mean absolute error was also utilized. The model that returns the smallest values for the loss functions is regarded as the suitable 
one for forecasting crude oil returns volatility. The result obtained showed that the AP-ARCH $(1,1)$ outperformed other models with the skewed Student-t error distribution. This result is not in tandem with the findings of (Muhammed and Faruk, 2018) which reported the GARCH (1,1)-GED to be the model that performs better crude oil price volatility forecast than other GARCH-type models. This, in essence, calls for further research on GARCH modelling of crude oil returns. We, therefore, recommend that the $\mathrm{AP}-\mathrm{ARCH}(1,1)$ under skew student-t error innovation should be adopted for fitting and forecasting crude oil returns volatility. Our result clearly indicates that the best-suited model for modelling crude oil returns in Nigeria is also the best in the evaluation of forecast performance. This is in tandem with the saying of (Dana, 2016) that the best fitting model is also the best for forecasting. The opposite is true for other studies that reported that best fit models are not necessarily the best in terms of forecast.

\section{Conclusion}

In this study, we considered a symmetric and three classes of asymmetric GARCH models for modelling and evaluating the characteristics of the conditional volatility of crude oil returns in Nigeria. Six error innovations, namely: The Student- $t$, generalized error, normal distribution and their skewed variant were utilized for fitting and evaluating the performance of $\operatorname{GARCH}(1,1), \operatorname{GARCH}(1,2), \operatorname{GARCH}(2,1)$, GARCH $(2,2)$, AP-ARCH $(1,1)$, GJR-GARCH $(1,1)$, and E-GARCH $(1,1)$ in capturing the dynamics of data on daily COR. This study reported that the crude oil return series exhibit persistence and asymmetry to shocks of volatility during the study period. The outcome of this study has some pertinent implications. One of which is that all the models performed creditably well during the fitting phase since they were mostly able to capture stylized facts of volatility clustering and persistence. We discovered that the skew Student-t error innovation outperformed most of the other innovations in most of the models. This has provided evidence that persistent or permanent volatility can be linked to price shocks, which in essence means that any political, economic or disease outbreak shock like COVID-19 which enhances volatility would last long and it is therefore necessary for policy-makers to come up with strategies to absorb the lasting effects of shocks for CRP. Our findings give credence to the APARCH $(1,1)$ as the best model in fitting and forecasting crude oil prices in Nigeria amongst the competing GARCH models.

\section{Acknowledgement}

We acknowledge Prof. Asiribo (Ahmadu Bello University, Zaria) for comments on the manuscript 


\section{References}

Abdullah, S. M., Siddiqua, S., Siddiquee, M. S. H., \& Hossain, N. (2017). Modeling and forecasting exchange rate volatility in Bangladesh using GARCH models: a comparison based on normal and Student's t-error distribution. Financial Innovation, 3(1): 1-19.

Agboola, S., Garba Dikk, H., \& Ebenezer A, O. (2018). On Exponentiated Skewed Student T Error Distribution on Some Volatility Models: Evidence of Standard and Poor-500 Index Return. Asian Journal of Applied Sciences, 11(1), 38-45.

Al Rahahleh, N., \& Kao, R. (2018). Forecasting Volatility: Evidence from the Saudi Stock Market. Journal of Risk and Financial Management, 11(4): 1-18.

Alhassan, A., \& Kilishi, A. A. (2016). Analysing Oil Price-Macroeconomic Volatility in Nigeria. CBN Journal of Applied Statistics, 7(1): 1-22.

Aliyev, F., Ajayi, R., \& Gasim, N. (2020). Modelling asymmetric market volatility with univariate GARCH models: Evidence from Nasdaq-100. Journal of Economic Asymmetries, 22(19):1-10.

Central Bank of Nigeria:: crude oil. (2020). Retrieved April 1, 2020, from https://www.cbn.gov.ng/rates/crudeoil.asp

Dana, A.-N. (2016). Modelling and estimation of volatility using ARCH/GARCH models in Jordan's stock market. Asian Journal of Finance \& Accounting, 8(1):152-167.

Deebom, Z. D., Essi, I. D., \& others. (2017). Modeling Price Volatility of Nigerian Crude Oil Markets Using GARCH Model: 1987-2017. International Journal of Applied Science and Mathematical Theory, 3(4), 23-49.

Fwaga, S.O., Orwa, G. and Athiany, H. (2017) Modelling Rates of Inflation in Kenya: An Application of GARCH and EGARCH Models. Mathematical Theory and Modelling, 7(5): 75-83.

Iddrisu, A.-K., Otoo, D., Abdul, I. W., \& Ankamah, S. (2019). Modeling and Forecasting of Ghana's Inflation Volatility. American Journal of Industrial and Business Management, 09(4): 930-949.

Iwada, E. M., Omoyeni, O. T., \& Temitope, A. (2018). Modeling Volatility in Selected Nigerian Stock Market. International Journal of Economics and Financial Management, 3(1): 30-43.

Kuhe, D. A., \& Agaigbe, P. T. (2018). Modelling Volatility of Naira/US Dollar Exchange Rate Dynamics Using Conditional Heteroskedasticity Models with Non-Gaussian Errors. Asian Research Journal of Mathematics, 11(3): 1-13.

Lin, Z. (2018). Modelling and forecasting the stock market volatility of SSE Composite Index using GARCH models. Future Generation Computer Systems, 79, 960-972.

Mattera, R., \& Giacalone, M. (2018). Alternative distribution based garch models for bitcoin volatility estimation. The Empirical Economics Letters, 17(11), 1283-1288.

Muhammed, G., \& Faruk, B. U. (2018). The relevance of GARCH-family models in forecasting Nigerian oil price volatility. 42(2): 1-20

Narayan, P. K., \& Narayan, S. (2007). Modelling oil price volatility. Energy Policy, 35(12), 6549-6553. 
Nguyen, D. K., \& Walther, T. (2020). Modeling and forecasting commodity market volatility with longterm economic and financial variables. Journal of Forecasting, 39(2), 126-142.

Okoro, C. N., \& Osisiogu, U. A. (2017). Evaluating the Volatility Forecasting Performance of EGARCH ( 1, 1 ) Models in USDNGN and USDZAR Exchange Rates. 35(6): 1000-1009.

Nyoni, T. (2018). Modeling and Forecasting Inflation in Zimbabwe: a Generalized Autoregressive Conditionally Heteroskedastic (GARCH) approach. Online at https://mpra.ub.unimuenchen.de/88132/ MPRA Paper No. 88132.

Samson, T. K. (2020). Modelling Volatility in Nigerian Stock Market : Evidence from Skewed Error Distributions. International Journal of Modern Mathematical Sciences. 18(1): $42-57$

Suleiman, S., Usman, U., \& Adamu, U. (2015). Modelling and Forecasting the Crude Oil Price in Nigeria. International Journal of Novel Research in Marketing Management and Economics, 2(1), 1-13.

Zhang, Y. J., Yao, T., He, L. Y., \& Ripple, R. (2019). Volatility forecasting of crude oil market: Can the regime switching GARCH model beat the single-regime GARCH models? In International Review of Economics and Finance. 7(59): 1-45. 